\title{
Outcome of Lateral Condyle Fracture of Humerus in Children Treated with Open Reduction and Internal Fixation
}

\author{
KC D ${ }^{1}$, Mishra $\mathrm{SM}^{2}$, Yogi $\mathrm{S}^{3}$, Shrestha $\mathrm{D}^{4}$, Karki $\mathrm{P}^{5}$, Shrestha $\mathrm{S}^{6}$
}

\begin{abstract}
Introduction: Lateral condyle fracture is one of the commonest injuries encountered in pediatric age group. There is no unanimity regarding the method of treatment, however closed reduction is not applicable to all cases and have failure rates making open reduction and internal fixation (ORIF) as the treatment of choice at least in displaced fractures. There are a number of options during surgical management of these fractures; Kirschner-wire (K-wire) is the most commonly used implant for fixation. The purpose of our study was to evaluate the results of lateral condyle fractures of humerus in children treated by ORIF by K-wires based on Hardacre criteria. Materials: This prospective study was conducted in the department of orthopedics in Nepalgunj Medical College Teaching Hospital, Kohalpur from May 2016 to October 2018. All of the fractures in this study were treated by ORIF with unburied K-wires. It included 37 children of age group upto 14 years. Children were evaluated for age, sex, side of arm involved, mechanism of injury, type of fracture, presence of additional injuries, implant removal time, outcome and accompanying complications. K-wires were removed after clinico-radiological union of the fractures. Patients were evaluated using the Hardacre criteria in follow up till 6 months. Result: In this study of 37 children, 28 (75.7\%) were males and 9 (24.3\%) were females. All of them were 14 years of age or less with mean age of $6.7 \pm 0.316$. Majority of fractures $(67.6 \%)$ were observed between six to ten years of age. Left side was predominantly involved (62.2\%). Milch type I fracture was found in 5 (13.5\%) children while Milch type II fracture were observed in $32(86.5 \%)$ children. The final outcome and functions were evaluated using Hardacre criteria in which $27(73 \%)$ cases had excellent result and all cases had good result as per Hardacre criteria. The complications were 10 (27\%) cases of lateral spur; eight (21.6\%) cases of hypertrophied scar and four (10.8\%) cases of pin track infection and 2 (5.4\%) of cubitus varus. Conclusion: The treatment of displaced lateral condyle fracture of humerus by open reduction and unburied K-wire fixation is safe, easy and cost effective procedure with good results. This modality of treatment provides good results among pediatric population without the need for second admission for implant removal.
\end{abstract}

\section{Key words: Hardacre criteria, K-wire, Lateral condyle fractures, Milch classification, ORIF}

1. Dr. Dipendra K.C.

2. Prof. S.M. Mishra

3. Dr. Sushil Yogi

4. Dr. Dinesh Shrestha

5. Dr. Prateek Karki

6. Dr. Sabin Shrestha

Address for correspondence:

Dr. Dipendra K.C.

Department of Orthopedics

Nepalgunj Medical College \& Teaching Hospital

Kohalpur, Banke, Nepal

Email: drdipendrakc@gmail.com

\section{INTRODUCTION}

In children upper extremity fractures constitute 65 to $75 \%$ of total pediatric fractures. Lateral condyle fractures of the distal humerus are the second most common fractures at the elbow in the pediatric population usually between the ages of six to 10 years old making up five to $20 \%$ of all distal humerus fractures in children ${ }^{1-5}$. The ossification center of the lateral condyle of the distal humerus on an average appears just before one year of age but may be delayed as late as 18 to 24 months ${ }^{6}$. The lateral condyle fuses with distal end of humerus usually in between 12 to 16 years with fusion occurring earlier in girls than in boys ${ }^{7}$. Before the fusion completes the lateral condyle may be sheared off or avulsed leading to fracture of lateral condyle which usually occurs in between six to 10 years of age ${ }^{3}$. On the basis of the fracture anatomy Milch in 1955 classified it into type I and type II. Type I fracture being the one exiting through the capitellotrochlear groove and Type II fracture being the one through the trochlea. Various modalities of implants are being used for open treatment of this fracture. Smooth pins are most commonly used implants for fracture fixation ${ }^{8}$. It has been observed that large number of pediatric patients come to the department of Orthopaedic at Nepalgunj Medical College Teaching Hospital, Kohalpur with displaced fracture of lateral condyle of humerus so it was thought worthwhile to study the clinical and radiological the pattern of fractures of lateral condyle of humerus and their outcome after open reduction with k-wires fixation. 


\section{MATERIALS AND METHODS}

The present prospective study was conducted in the Department of orthopedics at Nepalgunj Medical College Teaching Hospital Kohalpur, over the period of 30 months from May 2016 to October 2018. Only displaced lateral condyle fracture of humerus up to 14 years of age or below and less than 1 week old have been included in the study. Anteroposterior, olique and lateral $\mathrm{X}$-rays of the elbow were done to confirm the diagnosis and to study the morphology of the fracture. The fracture was classified according to the Milch classification. The fracture was approached via Kocher's incision and the fracture fragments was reduced and stabilized with K-wires and were left unburied outside the skin removal for easy removal. Wound was closed in layers followed by above elbow slab in 90 degrees of flexion with forearm in supinaton after dressing was done. All the patients were administered intravenous antibiotics for at least of three days and then converted to oral antibiotics. The dressing was changed after 48 hours of surgery and the children were generally discharged from hospital after 72 hours and second look dressing was advised to the patient party on $5^{\text {th }}$ to $7^{\text {th }}$ day. On $14^{\text {th }}$ post-operative day sutures were removed and above elbow slab was continued.

\section{FOLLOW UP}

Subsequently all the patients operated for lateral condyle fracture of humerus were followed up two weeks after the date of surgery and they were evaluated clinically and radiologically. Wound was inspected and sutures were removed. X-rays were done and the position of the fracture and position of the implants were checked. Limb was protected in above elbow slab.

There after the children were followed at five to seven weeks; 10 to 12 weeks; 16 to 18 weeks and 22 to 24 weeks time. At follow up between five to seven weeks time clinical and radiological evaluation was done to assess the progress of the union and complications. With the evidence of the union K-wires were removed and slab was discontinued and patients were advised for elbow ROM. From the third follow up onwards, patient were evaluated for pain, ROM, radiological evidence of union, carrying angle and complications.

The outcome based on the above observations were graded according to the system described by Hardacre et al $^{9}$.

\begin{tabular}{|l|l|}
\hline Excellent Result & $\begin{array}{l}\text { No symptoms+ Full ROM +No alteration } \\
\text { in the carrying angle. }\end{array}$ \\
\hline Good Result & $\begin{array}{l}\text { ROM deficit<150 of complete extension }+ \\
\text { inconspicuous alteration in the carrying angle } \\
+ \text { no arthritic or neurological symptoms. }\end{array}$ \\
\hline Poor Result & $\begin{array}{l}\text { Disabling loss of motion( }>150 \text { loss of } \\
\text { extension + conspicuous alteration in the } \\
\text { csarrying angle + Arthritic symptoms or } \\
\text { ulnar neuritis or X-ray findings of non- } \\
\text { union or AVN. }\end{array}$ \\
\hline
\end{tabular}

\section{OBSERVATION AND RESULTS}

There were 28 males (75.7\%) and 9 females (24.3\%) with male to female ratio being 3.1:1. Left limb was commonly affected, in 23 patients (62.2\%) and right being in 14 patients (37.8\%). The most common mode of injury was fall while playing at ground at 31 (83.8\%) followed by fall from height at $6(16.2 \%)$.

\begin{tabular}{|c|c|c|c|}
\hline Age in years & Frequency(n) & Percentage (\%) & Mean \pm SD \\
\hline $1-5$ & 10 & 27.0 & \\
\cline { 1 - 3 } $6-10$ & 25 & 67.6 & \multirow{2}{*}{$\begin{array}{c}6.73 \pm 1.92 \\
\text { years }\end{array}$} \\
\hline$>10$ & 2 & 5.4 & \\
\hline Total & 37 & 100.0 & \\
\hline
\end{tabular}

Table II: Distribution of age in total participants $(n=37)$

The mean age of the patient was $6.73 \pm 1.92$ years.

\begin{tabular}{|c|c|c|}
\hline Milch classification & $\begin{array}{c}\text { Number of } \\
\text { patients }(\mathbf{n})\end{array}$ & Percentage (\%) \\
\hline Type I & 5 & 13.5 \\
\hline Type II & 32 & 86.5 \\
\hline Total & $\mathbf{3 7}$ & $\mathbf{1 0 0}$ \\
\hline
\end{tabular}

Table III: Distribution type of lateral condyle fracture of humerus according to Milch classification in total participants $(n=37)$.

The fractures were mostly in Milch II at 32 (86.5\%)

\begin{tabular}{|c|c|c|c|}
\hline $\begin{array}{l}\text { Implant removal } \\
\text { period ( in weeks) }\end{array}$ & $\begin{array}{c}\text { No. of } \\
\text { patients }\end{array}$ & $\begin{array}{c}\text { Percentage } \\
\text { (\%) }\end{array}$ & Mean $\pm S D$ \\
\hline 5 & 11 & 29.7 & \multirow{4}{*}{$\begin{array}{c}5.78 \pm 0.58 \\
\quad \text { weeks }\end{array}$} \\
\hline 6 & 23 & 62.2 & \\
\hline 7 & 3 & 8.1 & \\
\hline Total & 37 & 100 & \\
\hline
\end{tabular}

Table IV: Distribution of duration of implant removal in total participants $(n=37)$

The mean duration of K-wire removal was $5.78 \pm 0.58$ weeks.

\begin{tabular}{|c|c|c|}
\hline $\begin{array}{c}\text { Hardacre criteria } \\
\text { at Final follow up }\end{array}$ & $\begin{array}{c}\text { Number of } \\
\text { patients(n) }\end{array}$ & Percentage (\%) \\
\hline Excellent & 27 & 73 \\
\hline Good & 10 & 27 \\
\hline Poor & 0 & 0 \\
\hline Total & 37 & 100 \\
\hline
\end{tabular}

Table V: Distribution of final outcome based on Hardacre et al9 criteria among total participants $(n=37)$

According to the criteria of Hardacre et al ${ }^{9}, 27$ cases (73\%) fell into excellent grade and 10 cases (27\%) fell into Hardacre good grade and in all patients there was no disabling loss of motion, conspicuous alteration of carrying angle, arthritic symptoms, ulnar neuritis, nonunion and avascular necrosis. 
KC et al.: Outcome of Lateral Condyle Fracture of Humerus in Children Treated with Open Reduction and Internal Fixation

\begin{tabular}{|c|c|c|}
\hline Complications & No. of patients(n) & Percentage (\%) \\
\hline Lateral spur & 10 & 27.02 \\
\hline Hypertrophic Scar & 8 & 21.62 \\
\hline Pin track infection & 4 & 10.81 \\
\hline Cubitus Varus & 2 & 5.40 \\
\hline None & 13 & 35.13 \\
\hline Total & 37 & 100 \\
\hline
\end{tabular}

Table VI: Distribution of Complications encountered at final follow up among total participants $(n=37)$

The most common complication is Lateral spur formation (27.02\%) followed by hypertrohic scar (21.62\%). Out of 37 patients who had undergone ORIF for lateral condylar fractures, 2 patients (5.4\%) developed varus deformity which was mild and not noticeable and eight patients (21.62) had mild restriction (<15 degrees) without producing any noticeable inconvenience to patients at the final follow-up, the patients were send to further physiotherapy.

\section{DISCUSSION}

Lateral condyle fracture of humerus is the common pediatric elbow fracture after the supracondylar fracture of humerus ${ }^{1,2,4,5}$. The fractures of the lateral condyle of humerus are so called "fracture of necessity" always warrants the open reduction and internal fixation ${ }^{10}$. Though undisplaced fractures can also be treated conservatively through slab and immobilization but higher incidence of malunion, non-union and avascular necrosis of lateral condyle warrants proper anatomical reduction through internal fixation ${ }^{9}$.

Higher incidence of male as compared to the female in this study can be due to the more involvement of the males in outdoor activities. The lateral condyle fracture of humerus more often involve left elbow in approximately $50 \%$ to $70 \%$ children ${ }^{9,11,12}$ which is comparable to this study.

In various studies the outcome had varied widely. Hardacre et al. in his study observed $65.2 \%$ excellent; $13.1 \%$ good result and $21.7 \%$ poor result ${ }^{9}$. Cardona et al in his study observed $93.7 \%$ excellent and $6.3 \%$ good result ${ }^{13}$. Boz et al in his study observed $78.3 \%$ excellent result and $21.7 \%$ good result ${ }^{14}$. Leonidou et al in his study observed $96 \%$ of excellent result and four percent of good result ${ }^{15}$. Li et al in his study observed $73.3 \%$ of excellent result and $26.7 \%$ good result in children treated with open reduction and k-wire fixation ${ }^{10}$. Bashir et al observed that $56 \%$ cases were excellent result and $44 \%$ of good result ${ }^{12}$.

In the present study of 37 children with lateral condyle fracture of humerus, final outcome evaluated at final follow up in between 22 to 24 weeks was 27 cases (73\%) had excellent result and ten cases (27\%) had good result.

\section{Complications}

The complications encountered among various studies were nonunion; pin track infection; migration of K-wires; lateral

overgrowth and hypertrophic scar. Hardacre et al in his study observed $1.9 \%$ of non-union; $1.9 \%$ of pin track infection; $7.6 \%$ of migration of K-wires and $23.1 \%$ of lateral overgrowth ${ }^{9}$. Boz et al in his study encountered $47.8 \%$ of lateral bony overgrowth ${ }^{14}$. Li et al in his study observed $36.7 \%$ of lateral prominence ${ }^{10}$. Bashir et al in his study encountered two percent of pin track infection; $10 \%$ of cubitus varus deformity; $68 \%$ of lateral bony overgrowth and eight percent of hypertrophic scar ${ }^{12}$.

In present study of 37 people, lateral spur and hypertrophic scar was noticed at $10(27.02 \%)$ and eight cases $(21.6 \%)$ respectively. Four cases $(10.8 \%)$ had pin track infection which resolved after removal of K-wires and use of oral antibiotics and two cases (5.4\%) had cubitus varus which was not obvious cosmetically.

\section{CONCLUSION}

The treatment of displaced lateral condyle fracture of humerus by open reduction and K-wire fixation is safe and cost effective with excellent results. The removals of unburied K-wires are easy and can be done in outpatient basis which removes the need for second surgery. This modality of treatment decreases the duration of total hospital stay in pediatric school going children by removing the need of second surgery during implant removal, however a randomized controlled trial with larger sample size would increase the significance of this study.

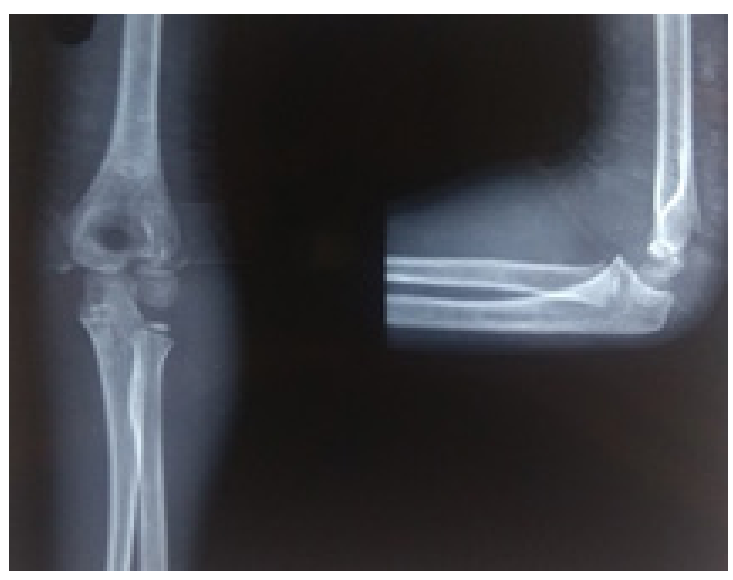

Figure 1 : X-ray AP and lateral view of elbow after injury

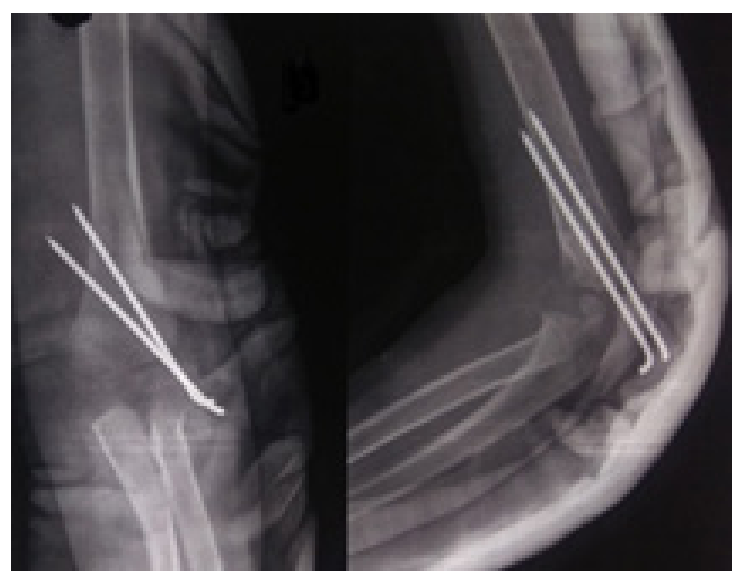

Figure 2 : X-ray Ap and lateral view on 1st post operative day 


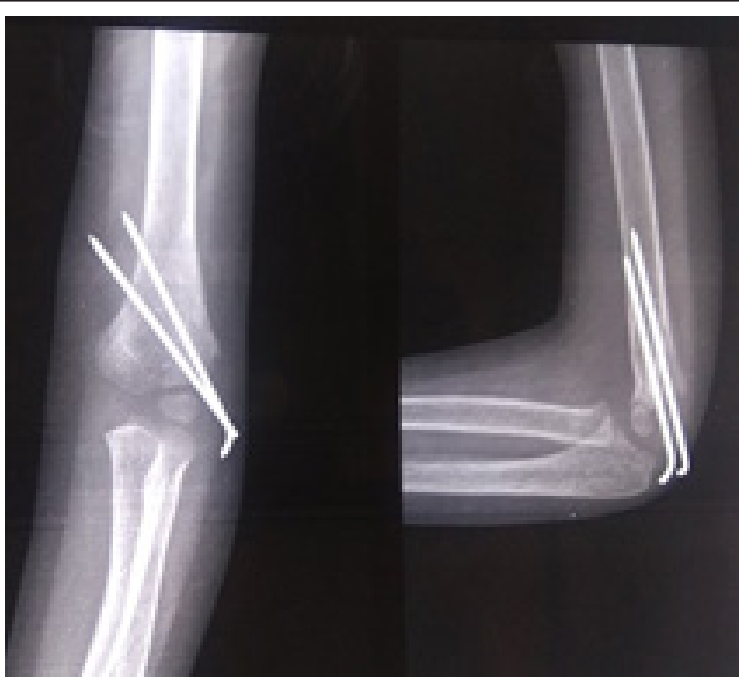

Figure 3 : X-ray AP and lateral view elbow on follow up

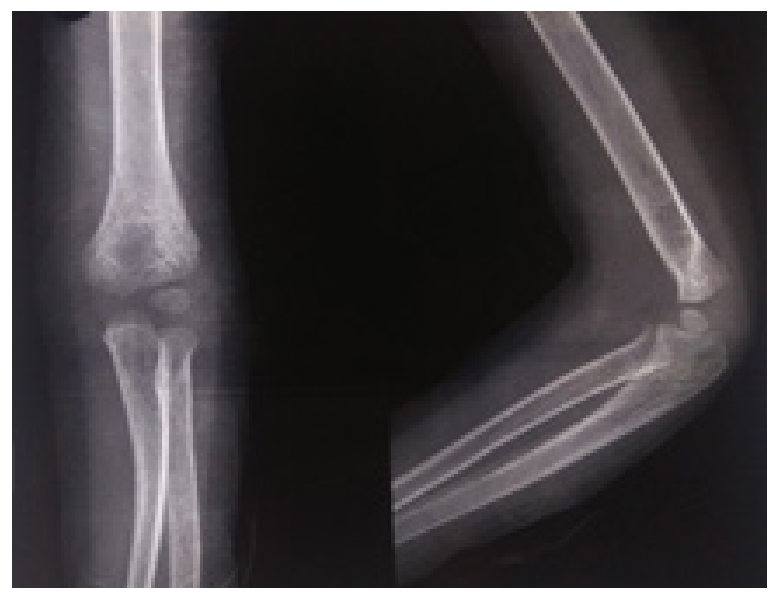

Figure 4 : X-ray AP and lateral view elbow after implant removal during follow up.

\section{REFERENCE}

1. Foster DE, Sullivan JA, Gross RH. Lateral humeral condylar fractures in children. J pediatr orthop. 1985;5(1):16-22.

2. Badelon O, Bensahel H, Mazda K, Vie P. Lateral humeral condylar fractures in children: a report of 47 cases. J pediatr orthop. 1988;8(1):31-4.

3. Beaty JH, Kasser JR. The elbow region: general concepts in the pediatric patient. In: Bucholz RW, Heckman JD, Court-brown C, editors. Rockwood and Wilkin's fractures in children. 6th ed. Philadelphia: Lippincott Williams \& Wilkins; 2006. vol 1 p. 53041.

4. Song KS, Kang $\mathrm{CH}$, Min BW, Bae $\mathrm{KC}$, Cho $\mathrm{CH}$. Internal oblique radiographs for diagnosis of nondisplaced or minimally displaced lateral condylar fractures of the humerus in children. J Bone Joint Surg Am. 2007;89(1):58-63.

5. Marcheix PS, Vacquerie V, Longis B, Peyrou P, Fourcade L, Moulies D. Distal humerus lateral condyle fracture in children: when is the conservative treatment a valid option ? Orthop Traumatol Surg Res. 2011;97(3):304-7.

6. Buhr AJ, Cooke AM. Fracture patterns. Lancet 1959;1(7072):531-6.

7. Brodeur AE, Silberstein MJ, Graviss ER, Luisiri A. The basic tenets for appropriate evaluation of the elbow pediatrics. Curr Probl Diagn Radiol. 1983;12(5):5-28.
8. Jakob R, Fowles JV, Rang M, Kassab MT. Observations concerning fractures of the lateral humeral condyle in children. J Bone Joint Surg Br. 1975;57(4):430-6.

9. Hardacre JA, Nahigian SH, Froimson Al, Brown JE. Fractures of the lateral condyle of the humerus in children. J Bone Joint Surg. 1971;53(6):1083-95.

10. Li WC, Xu RJ. Comparison of Kirschner wires and AO cannulated screw internal fixation for displaced lateral humeral condyle fracture in children. Int Orthop. 2012;36(6):1261-6.

11. Patwardhan S, Tembhurne A, Shyam AK, Sancheti PK. Effect of fracture classifications on outcome of lateral condyle humerus fracture in children-prospective study. J Orthop. 2011;1(1):70.

12. Bashir A, Baba BA, Khan HA, Wani MI, Rashid S. Managing paediatric un-stable lateral condyle fractures of humerus with unburried Kirschner wires. Indian J Orthop Surg. 2016;2(4):31821.

13. Cardona JI, Riddle E, Kumar SJ. Displaced fractures of the lateral humeral condyle: criteria for implant removal. J Pediatr Orthop. 2002;22(2):194-7.

14. Unal B, Ulusal AE, Vuruskaner $\mathrm{H}$, Aydinoglu Y. Functional results of displaced lateral condyle fractures of the humerus with fourweek K-wire fixation in children. Acta Orthop Traumatol Turc. 2005;39(3):193-8.

15. Leonidou A, Chettiar K, Graham S, Akhbari P, Antonis K, Tsiridis E, et al. Open reduction internal fixation of lateral humeral condyle fractures in children. A series of 105 fractures from a single institution. Strategies Trauma Limb Reconstr. 2014;9(2):73-8. 